\title{
A Q-Analysis of Values and Attitudes Toward Advertising
}

\author{
Editorial and advertising \\ students hold differing views \\ of advertising's social value; \\ those of the latter are more \\ or less consistent with those \\ of practitioners, but not so \\ for the editorialists.
}

- In the folklore of advertising there is an oft stated belief that "it takes a special kind of person to succeed in advertising." But, the qualities which this special person must possess differ depending on whether the speaker is a critic of advertising or an apologist for advertising.

For example, the critic of advertising believes that the individual who is capable of succeeding in advertising must be one of those "young people perfectly socialized to the current system, who will enthusiastically practice the pecuniary ethic of legal innocence."1 $\mathrm{Or}$, he is one of the "verbally bright who have no zeal for a serviceable profession and who have no particular scientific or artistic bent. For the most part they make up the tribes of salesmanship, entertainment, business management, promotion and advertising. Here of course there is no question of utility or honor to begin with so an ingenuous boy will not look here for a manly

- Dr. Larkin is assistant professor of journalism at the University of Oklahoma, Norman. This article is based on his Ph.D. dissertation at the University of Iowa School of Joumalism. career." 2 On the other hand the critics also feel that "youngsters with a traditional ethical sense avoid (advertising)."s

While much has been written concerning the "type" of person who is either willing or capable of succeeding in advertising, little has been done to determine, empirically, if such types actually exist, and if there really is any correlation between the basic ethical beliefs and attitudes of these individuals and the careers they elect to pursue.

\section{Method}

In an effort to gain information which might shed some light on these questions, the following study was conducted. First, in order to gain some insights into an individual's beliefs, attitudes and values as they relate to broad social and ethical questions, a set of 64 Q-statements was assembled. These statements dealt with eight basic ethical questions-frugality, temperance or moderation, productivity, rationality, truth, benevolence, human dignity and a hierarchy of values.

Of the 64 statements, 32 were phrased so as to support and reflect the traditional interpretation of each of these eight virtues. For example, in relation to the question of the need to be thrifty and frugal the traditional idea is that it is better to save than to spend, and it is wrong to go into debt.

\footnotetext{
1 Jules Henry, Culture Against Man (New York: Random House, 1963), p. 97.

Paul Goodman, Growine $U_{p}$ Absurd (New York: Random House, 1956), p. 25.

Henry, loc. clt.
} 
Therefore, the statements supporting this interpretation said, "The only way to achieve real financial security is to save a portion of our income on a regular basis," and "Our nation was built on savings and investments. We seem to have forgotten all this in the urge to spend and spend some more."

The other 32 statements in this set were designed to reflect a more liberal interpretation of these same eight virtues. For example, "People who still save enough money first and then go out and buy a product are really denying themselves the benefits of our economy of abundance," and "In our economy of abundance it is perfectly acceptable to spend our entire income and not worry about saving."

The 64 statements in this set were gathered from a number of depth interviews conducted with individuals who were asked to discuss at length their attitudes on a number of broad social and ethical questions, and from statements included in a number of published works on social and religious ethics. In the same manner statements were also gathered relating to the individual's attitudes toward advertising as he feels it is, and should be, functioning in relation to our society, our economy and our system of values.

From these latter statements two additional sets were constructed, one containing statements concerning the way advertising is actually functioning in these three areas, the other containing statements concerning how it should be functioning. Each of these two sats contained 80 statements; 40 reflecting a negative or detrimental effect, and 40 reflecting a positive or beneficial effect.

The statements in these two sets were further broken down to reflect the individual's attitude toward advertising's effect on five economic areas, seven relating to society and seven relating to our system of values." For example, two statements were constructed which

\footnotetext{
4 An outline of the categories used in this study is available upon request.
}

reflected a positive or beneficial effect that advertising is having on economic competition (e.g., "Advertising encourages the small manufacturer to compete with larger competitors by enabling him to tell a large audience about his product quickly and efficiently.") Two statements were also constructed which reflected a negative or detrimental effect (e.g., "Advertising encourages the formation of monopolies by giving the larger company with more money the opportunity to use more advertising and drive the smaller companies out of business.")

Each statement was typed on a separate slip and assembled into three Qdecks. Respondents were selected in such a way as to compare the beliefs, attitudes and values of individuals who were either anticipating a career in advertising, or already in advertising, with those who had opted for some other profession. Thus the subjects were selected from four vocational groups: 1) students of advertising, 2) news/editorial students, 3) advertising practitioners and 4) news/editorial practitioners. Six subjects were selected from each category for a total of 24 respondents.

In order to gain as great a range of respondent types as possible, and to avoid the possibility of bias due to the inclusion of respondents with homogeneous characteristics, an effort was made to select students with both high and low academic standing in their chosen sequence, and with a range of interest levels regarding their chosen career. A similar effort was made in relation to the practitioners with selection based on age and the number of years in the profession.

\section{Results}

In analyzing the first set of statements-those dealing with beliefs and attitudes regarding basic ethical questions-two distinct types of respondents can be identified. One of these types might (for the sake of easy identification) be labeled "Ethical Liberals." In- 
dividuals included in this group tend to agree with those statements reflecting the more liberal interpretation of the religious and social ethics such as "Appeals to an individual's emotions are as valid and acceptable as appeals to his rational side," and "Our Victorian ethics and morals are no longer useful in our present day society and should be changed."

These same individuals tended to reject or disagree with those statements which were designed to reflect the more traditional interpretation of these same ethical factors, such as "The constant encouragement to spend rather than to save money is a threat to our economy," and "No laxity or wavering in moral standards should be permitted."

The second type of individual identified by the analysis of this deck could be called "Ethical Traditionalist." This group' tended to agree with those statements which were designed to reflect the more traditional interpretation of ethical values, such as "Work is essential to the well-being of the individual and our society," and "Moderation or self-restraint is a virtue which everyone should practice today."

This group tended to reject those statements which were designed to reflect the more liberal interpretation of these same ethical values, such as "People who still save enough money first and then go out and buy a product are really denying themselves the benefits of our economy of abundance," and "In our economy of abundance it is perfectly acceptable to spend our entire income and not worry about saving."

Of the 11 individuals who clustered in the Ethical Liberal group, eight were students and three were practitioners. (Table 1.) Of the eight students, five were advertising students, and three were editorial students. Of the three practitioners all were in advertising.

Of the 13 individuals who clustered in the Ethical Traditionalist group nine were practitioners, and four were students. Of the nine practitioners six were editorial practitioners, and three were advertising practitioners. Of the four students, three were editorial students, and only one was an advertising student.

Analysis of the subjects' sorting of the second deck of statements-those dealing with attitudes toward advertising as they believe it is actually functioning-again indicates two distinct types of respondents. One of these can be described as "Pro-Advertising." These individuals tended to agree strongly that advertising is serving a beneficial function in relation to our economy and our society, and that it is having no detrimental effects on our system of values. Statements with which they agree include, "By introducing new products advertising forces competition to constantly attempt to develop new or improved products," and "Most of today's advertising is informative and truthful in its presentation of the facts about the product." They tended to reject or disagree with statements about detrimental effects, such as "Advertising is threatening to destroy our traditional values and replace them with a more materialistic attitude," and "Too much of today's advertising relies on exaggeration, halftruths, and deception in order to sell a product."

The second type of individual identified by the analysis of the second deck could be described as the "Anti-Advertising" group. Individuals in this group tended to agree strongly that advertising is having very detrimental effects on our society and is eroding our system of values: "Much of today's advertising is an insult to the basic dignity of man," and "Too much of today's advertising relies on exaggeration, half-truths, and deception in order to sell a product." They disagreed strongly with such statements as "Advertising encourages us to be rational by presenting us with the facts about a product and then letting us judge its worth on the basis of this information," and 
TABLE 1

Distribution of Subjects Across Attitude Types

Occupation
Classification

Ad Students

Ed Students

Ad Practitioners

Ed Practitioners

Ethical
Liberals
5
3
2
0

"Very little of today's advertising is in poor taste."

Of the 16 individuals in the Pro-Advertising group, six were advertising students, six were advertising practitioners and four were editorial practitioners. Of the eight described as AntiAdvertising, six were editorial students, and two editorial practitioners.

In an effort to determine which areas of our economy, our society and our system of values are being affected by advertising-either pro or con-a comparison of the individuals' sorting of the second deck - statements regarding how advertising is actually functioningand their sorting of the third deckhow advertising should be functioning -was made.

The 16 Pro-Advertising individuals found few areas in which advertising is not living up to their expectations. However, for the eight individuals in the Anti-Advertising group there is considerable difference between their attitude concerning the way advertising is actually functioning and the way it should be functioning.

This second group is most concerned with effects on our society and its system of values, and less with economic effects. Correlation coefficients showing the degree of relationship between sorts on these two decks are given in Table 2.

To briefly recap the beliefs, attitudes and values of the 24 subjects:

Of the six advertising students, five were Ethical Liberals, and one was an Ethical Traditionalist. All six were Pro-Advertising in their attitudes con-

$\begin{array}{ccc}\begin{array}{c}\text { Ethical } \\ \text { Traditionallsts }\end{array} & \begin{array}{c}\text { Pro } \\ \text { Advertising }\end{array} & \begin{array}{c}\text { Anti } \\ \text { Advertising }\end{array} \\ 1 & 6 & 0 \\ 3 & 0 & 6 \\ 3 & 6 & 0 \\ 6 & 4 & 2\end{array}$

TABLE 2

Correlation Between Decks 2 and 3

\begin{tabular}{|c|c|c|}
\hline $\begin{array}{l}\text { Respondent } \\
\text { Number }\end{array}$ & Identification & Correlation (r) \\
\hline 1 & Ad Student & .23 \\
\hline 2 & Ad Student & .52 \\
\hline 3 & Ad Student & .37 \\
\hline 4 & Ad Student & .30 \\
\hline 5 & Ad Student & .32 \\
\hline 6 & Ad Student & .43 \\
\hline 7 & Ed Student & -.12 \\
\hline 8 & Ed Student & -.41 \\
\hline 9 & Ed Student & -.22 \\
\hline 10 & Ed Student & -.44 \\
\hline 11 & Ed Student & .05 \\
\hline 12 & Ed Student & -.35 \\
\hline 13 & Ađ Practitioner & .42 \\
\hline 14 & Ad Practitioner & .26 \\
\hline 15 & Ad Practitioner & .30 \\
\hline 16 & Ad Practitioner & .44 \\
\hline 17 & Ad Practitioner & .30 \\
\hline 18 & Ad Practitioner & .27 \\
\hline 19 & Ed Practitioner & .20 \\
\hline 20 & Ed Practitioner & -.13 \\
\hline 21 & Ed Practitioner & .19 \\
\hline 22 & Ed Practitioner & .33 \\
\hline 23 & Ed Practitioner & .29 \\
\hline 24 & Ed Practitioner & .20 \\
\hline
\end{tabular}

cerning how advertising is and should be functioning.

Of the six editorial students, three were Ethical Liberals, and three were Ethical Traditionalists. All six were Anti-Advertising. All felt advertising is not functioning the way it should.

of the six advertising practitioners two were Ethical Liberals, and four were Ethical Traditionalists. Like the 
advertising students, all were Pro-Advertising.

Finally, of the six editorial practitioners, all were Ethical Traditionalists; four were Pro-Advertising, and two were Anti-Advertising.

\section{Discussion}

A tendency is seen here for the students to be more liberal than the practitioners in their interpretation of basic ethical questions. Eight of the 12 students can be identified as Ethical Liberals. Of this group the most liberal of all are those who are preparing for a career in advertising. (Five of six advertising students fell in this category).

Considering that nine of the 12 practitioners fell into the Ethical Traditionalist category some interesting questions are raised. First, what changes take place in an individual's outlook after he enters his chosen profession? Must we expect his views to become less liberal?

What do the data regarding attitudes toward advertising suggest? First, and not too surprisingly, both the advertising students and the advertising practitioners hold the attitude that advertising is beneficial.

However, what does raise some questions are the attitudes of the six editorial students who are unanimous in their agreement that advertising is detrimental and the four editorial practitioners who hold the attitude that advertising is not detrimental. Did the latter always hold this attitude, or has it changed since they entered the profession? It is of interest that the four editorial practitioners who believe advertising is beneficial are all the younger members of the group-only two individuals over 50 hold an attitude similar to that of the editorial students.

In conclusion, there seems to be a suggestion that the individual who contemplates a career in advertising may indeed have a certain set of basic values which he holds in common with other individuals contemplating a similar vocation. However, to say that they are "perfectly socialized to the current system," and that they will "enthusiastically practice the pecuniary ethic of legal innocence," is by no means substantiated.

\section{PUBLIC SCHOOL NEWS COVERAGE (Continued from page 67)}

obtained a higher financial return from their tax assessments per pupil.

On the basis of proportion rather than quantity of school news stories, the director districts tended to "emphasize" the multicolumn stories with the multicolumn picture and isolated multicolumn picture stories. The director system stories' higher proportion of multicolumn pictures is noteworthy when one considers the attention value of the picture and the commonly accepted thesis that "a picture is worth a thousand words." Multicolumn pictures suggest action or group pictures whereas the single-column pictures usually are handout photographs of one individual. Since the director system had more multicolumn pictures perhaps someone other than newspaper photographers was providing the pictures.
This variable in itself did not prove statistically significant in the study, but the reasoning behind this variable was derived from comments made by two of the three directors during the interviews.

In general the newspaper editors of the director districts were more highly satisfied with the school news sources and news copy than the editors serving the non-director districts.

Upon consideration of the statistical evidence and descriptive data, it is reasonable to conclude that the school districts with public relations directors had a more balanced and sophisticated public information system. Likewise, these districts more fully utilized the communities' tax assessment bases which in turn supported their higher expenditures per pupil. 